\title{
Geochemical and Physical Aspects of Diamonds from the Akwatia and Tarkwa Diamondfields in Southern Ghana, West Africa
}

Ward, J.R., and Norman, D.I.

Earth and Environmental Sciences Department, New Mexico Institute of Mining and Technology, Socorro, NM USA.

Ghana has two diamond producing areas: Akwatia and Tarkwa (southeastern and southwestern Ghana, respectively). There is a known kimberlite source for the Akwatia diamonds. It was hypothesized that the Tarkwa diamonds, hosted in Tarkwaian sediments, originated in the Akwatia area. One thousand eighty diamonds totaling 37.075 carats were collected from Akwatia and Tarkwa sites. These samples were classified by their physical attributes and crystalline inclusions were then separated and geochemically analyzed. The occurrences of Tarkwa diamonds were also mapped.

Fifty two percent of the Tarkwa diamonds are colorless, with 23.7 percent slightly yellow or yellow. Twelve percent are green or yellowish green in color while few brown or grey diamonds are present. The morphology of the diamonds at Tarkwa is primarily dodecahedral $(36.1 \%)$, with an additional 23.1 percent octahedrons. Severely broken stones account for 30.6 percent. Nearly all (94.7\%) of the Tarkwa diamonds fluoresce colors including, in order of abundance, white, blue, yellowish brown, greenish yellow, yellowish orange, reddish orange and bright red. Garnet, orthopyroxene, and olivine inclusions from Tarkwa are all subcalcic (harzburgitic). The magnesium number for olivines range from 92.16 to 94.04 . The magnesium number for orthopyroxenes range from 93.30 to 94.56 . These numbers are lower than the worldwide trends for a harzburgitic paragenesis, but the calcium oxide content is low enough ( 0.00 to 0.05 , and 0.07 to 0.32 weight percent respectively) to preclude a lherzolitic paragenesis.

In contrast to the Tarkwa diamonds, forty percent of the Akwatia diamonds are yellow, 29.5 percent are colorless, and the remaining are yellowish grey, brown or grey. Diamond morphology also differs from Tarkwa in that 57.3 percent of the stones are octahedrons and 35.9 percent are dodecahedrons. Few are macles or broken stones. Fluorescence is also less common, occurring in only 63.6 percent of the samples. White and blue fluorescence dominates and only three percent show yellowish brown or yellowish orange color under ultraviolet light. The olivine and garnet inclusions from Akwatia also are harzburgitic. However, the magnesium numbers range from 92.45 to 93.19, lower than those from Tarkwa. In addition, Akwatia samples show higher chromium oxide content in both garnet and olivine inclusions. The average calcium oxide content remains constant among Ghanaian diamonds at 0.025 weight percent.

The morphology of the Tarkwa diamonds is consistent with alluvial transport. Mapping shows that Tarkwa alluvial diamonds in first and second order streams are associated with the contact between the Tarkwaian auriferous sands and Kawarie conglomerates. The occurrences follow this contact for $20 \mathrm{~km}$ around a paleobasin. 
We conclude that the differences in fluorescence and morphology of the Akwatia and Tarkwa diamonds indicate that the Tarkwa and Akwatia samples do not share a common geochemical origin. In addition, the dissimilarities in inclusion geochemistry support a geochemical origin for Tarkwa diamonds which is distinct from Akwatia diamonds. 